\title{
Thyroxine-Induced Changes in the Development of Neutral $\alpha$-Amino Acid Transport Systems of Rat Brain
}

\author{
Thomas R. Riggs, Kenneth G. Pote, Hae-Sook Im, and Daniel W. Huff \\ Department of Biological Chemistry, The University of Michigan, Ann Arbor, Michigan, U.S.A.
}

\begin{abstract}
Transport of representative neutral $\alpha$-amino acids was measured in brain slices after injecting thyroxine into donor rats of various ages from 1 to 23 days old. The hormone did not alter uptake in slices from 1day-old rats even when treatment was begun on pregnant rats as much as 10 days before delivery. Injecting thyroxine until age 6 days, however, decreased the activity of transport system A (the major sodium-dependent system in most mammalian cells) and caused appearance of a new transport system used by the model amino acids, 2-aminoisobutyric acid and 2-(methylamino)isobutyric acid. Uptake at 6 days was similar to that found in slices from older, untreated rats (e.g., those 14 days old). These
\end{abstract}

results strongly suggest that one action of thyroxine is to accelerate the development of neutral $\alpha$-amino acid transport systems of brain over the first six days after birth. Thyroxine treatment of rats from birth to age 14 days also appears to increase the activities of both system $A$ and the second transport system used by the two model amino acids in brains from 14-day-old rats. Key Words: BrainTransport systems-Thyroxine-Amino acids-Development-Rats. Riggs T. R. et al. Thyroxine-induced changes in the development of neutral $\alpha$-amino acid transport systems of rat brain. J. Neurochem. 42, 1260-1268 (1984).
A thyroid hormone deficiency during development of the brain of an animal can impair the growth and maturation of the central nervous system and produce irreversible mental retardation (Eayrs, 1961). Growth and development involve many metabolic events, including synthesis of new protein, and protein synthesis is one of the processes stimulated by thyroid hormones (Gelber et al., 1964; Geel et al., 1967). In addition, these hormones increase transport of at least some amino acids into tissues, including transport into rat brain in vivo (Daniel et al., 1975). The elevated uptake would be necessary to supply the amino acids required intracellularly for net synthesis of protein. Changes in amino acid transport would, therefore, be expected in response to thyroid hormone during the period of rapid brain development.

In the first paper in this series (Riggs et al., 1984), we have described some of the changes in neutral $\alpha$-amino acid transport systems that occur in rat brain over the first 3 weeks after birth. It is over this period that the major development of the rat brain takes place (Dobbing, 1971). This is also the time during which thyroid hormone is required for brain development in the rat (Hamburgh et al., 1964). In the present paper, we show the effects of thyroxine on transport of neutral $\alpha$-amino acids into brain slices from rats aged 1-23 days and describe some of the changes that occur in their transport systems in response to thyroxine.

\section{MATERIALS AND METHODS}

Procedures were similar to those reported earlier (Riggs et al., 1984). Newborn rats (Sprague-Dawley origin) were maintained with their mothers in groups of 810 pups each. Animals were grouped at random into five age ranges for most studies: 1-day group, rats from birth up to $24 \mathrm{~h}$ old; 6-day group, rats 5-7 days old; 10-day group, those 10 or 11 days old; 14-day group, those 1315 days old; and 23-day group, those 22-24 days old.

To produce hyperthyroidism, one group of pups was injected subcutaneously with $0.1 \mathrm{ml}$ of thyroxine penta-
Received July 26, 1982; revised August 2, 1983; accepted October 21, 1983.

Address correspondence and reprint requests to Dr. Thomas R. Riggs, Department of Biological Chemistry, The University of Michigan, Ann Arbor, MI 48109, U.S.A.
Abbreviations used: AIB, 2-Aminoisobutyric acid; Cycloleucine, 1-Aminocyclopentane carboxylic acid; MeAIB, 2-(Methylamino)isobutyric acid; PTU, Propylthiouracil. 
hydrate in $0.9 \% \mathrm{NaCl}$ solution alkalinized with $0.01 \mathrm{M}$ sodium phosphate buffer medium, $\mathrm{pH}$ 10. Some control animals received the alkalinized saline solution alone; however, some pups did not receive injections, since the same results were obtained. In the initial experiments, thyroxine was given according to the dosage schedule used by Hamburgh et al. (1964): pups aged $0-7$ days received $0.5 \mu \mathrm{g} /$ day; those $8-14$ days got $1.0 \mu \mathrm{g} /$ day; those $15-21$ days, $1.5 \mu \mathrm{g} / \mathrm{day}$; and those $22-30$ days, $2 \mu \mathrm{g} / \mathrm{day}$. For later experiments, animals 0-9 days old received 1 $\mu g$ of thyroxine every other day, and those 10 days and older got $2 \mu \mathrm{g}$ every other day. No differences in results were found between the two treatment schedules.

Two additional groups of rats were studied in the early experiments: one group in which pregnant rats and mothers received $0.1 \%$ propylthiouracil (PTU) in their drinking water throughout the entire experimental period (hypothyroid), and another group that received both the PTU and thyroxine injections.

Brain slices $0.4 \mathrm{~mm}$ thick were prepared from cerebral hemispheres with a McIlwain tissue chopper. They were incubated then in most cases in Krebs-Ringer bicarbonate medium containing $10 \mathrm{~m} M$ glucose and ${ }^{14} \mathrm{C}$-labeled amino acid, with continuous gassing with $95 \% \quad \mathrm{O}_{2}-5 \% \quad \mathrm{CO}_{2}$. Studies on inhibition of uptake and other experimental details were the same as described previously (Riggs et al., 1984). All $\left[{ }^{14} \mathrm{C}\right]$ amino acid levels in brain were calculated for intracellular water with the values for water distribution and space reported earlier for control and thyroxine-treated rats at each age (Riggs et al., 1984). Some results are expressed as distribution ratio, which is the ratio of level of $\left[{ }^{14} \mathrm{C}\right]$ amino acid in intracellular water to that in incubation medium.

\section{RESULTS}

Effect of thyroxine treatment in vivo on transport of amino acids into brain slices from rats of different ages

Injecting donor rats with thyroxine from birth resulted in significant decreases in uptakes of both 2aminoisobutyric acid (AIB) and alanine in tissues at day 6 (Figs. 1 and 2). A more detailed study with AIB showed this effect at all levels less than about $15 \mathrm{~m} M$ (see discussion of Fig. 4, below). With 2(methylamino)isobutyric acid (MeAIB), hormone pretreatment gave a stimulation of uptake with $0.5-$ $1 \mathrm{~m} M$ levels of the amino acid (Fig. 2), but gave only inhibition at higher levels. This difference appears to be a result of a thyroxine-induced change in the kinetics of uptake of this amino acid (see discussion of Fig. 3).

No effect of thyroxine treatment was found on AIB uptake at 1 or 3 days; but cycloleucine uptake (1 $\mathrm{mM}, 30 \mathrm{~min}$ incubation) was elevated by hormone treatment for 3-4 days (distribution ratios of $11.63 \pm 0.58$ for six samples in controls and 13.25 \pm 0.38 for eight samples after hormone treatment; $\mathrm{p}<0.05$ ). At 10 and 14 days, uptakes of $1 \mathrm{mM}$ levels of both AIB and MeAIB were stimulated by the hormone (Figs. 1 and 2). Alanine transport was

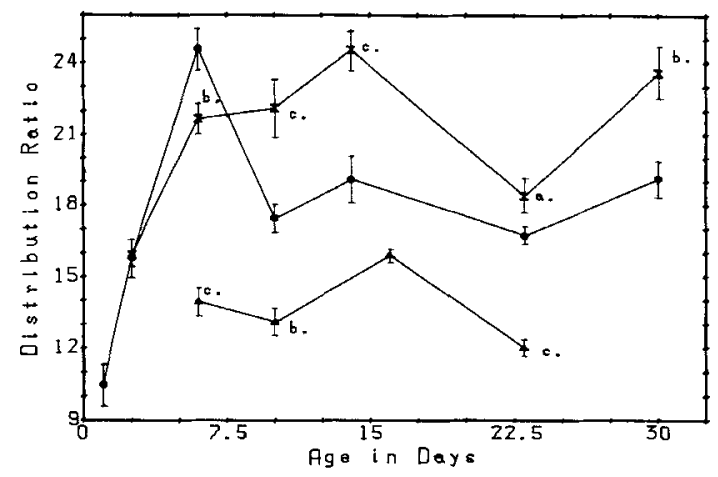

FIG. 1. Effects of thyroxine and PTU on uptake of AIB by brain slices from rats of different ages. Uptake of $1 \mathrm{mM}$ $\left[{ }^{14} \mathrm{C}\right] \mathrm{AIB}$ was measured for $30 \mathrm{~min}$ in normal Krebs-Ringer bicarbonate medium. Thyroxine and PTU treatments were as given in Materials and Methods. Values are averages \pm SEM for 4-29 samples per group. The vertical bars represent one standard error on each side of the average value. $\bullet$, control; $X$, thyroxine-treated; $\Delta$, PTU-treated. Statistical comparisons, thyroxine- or PTU-treated versus control: ${ }^{a} p<0.05$; ${ }^{b} p<$ $0.01 ;{ }^{c} p<0.001$.

increased at 22 days when a $1 \mathrm{~m} M$ level of the amino acid was used, although the stimulation was not statistically significant with a $0.5 \mathrm{mM}$ level (Fig. 2). The data of Fig. 1 show that uptake of AIB in the hormone-treated tissues remained fairly constant from 6 to 30 days of age except for a drop at 23 days. Since transport into control tissues decreased after 6 days, the net effect was a statistically significant stimulation of AIB uptake at the ages studied beyond 6 days (Fig. 1).

Treatment of donor rats with PTU resulted in greatly reduced uptake of AIB at ages 6-23 days

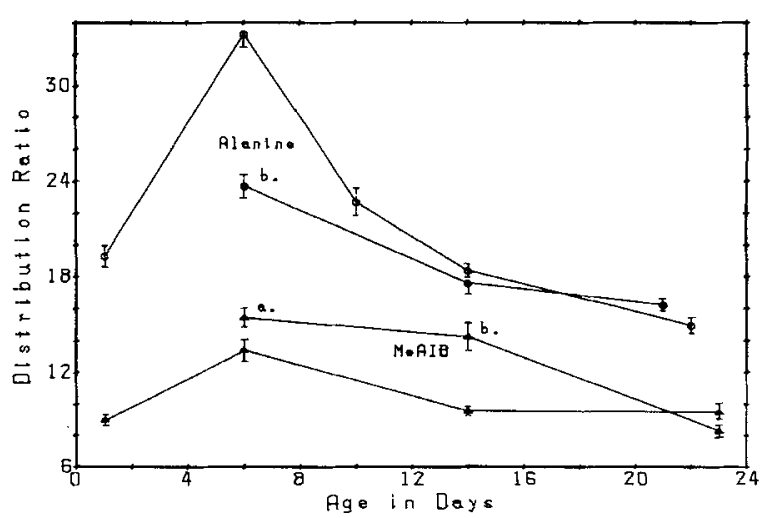

FIG. 2. Effect of thyroxine on uptakes of MeAIB and alanine by brain slices from rats of different ages. Uptakes of $0.5 \mathrm{mM}$ alanine $(0,0)$ or $1 \mathrm{mM}$ MeAlB $(\Delta, \Delta)$ were measured for 30 $\mathrm{min}$ in normal Krebs-Ringer bicarbonate medium. Thyroxine treatment was as described in Materials and Methods. $O$ and $\Delta$, controls; - and $\boldsymbol{\Delta}$, thyroxine-treated. Values are averages of 6-25 samples \pm SEM for MeAIB and of 10-44 values each for alanine. The vertical lines represent one standard error around the average. Statistical comparisons, thyroxinetreated versus controls: ${ }^{a} p<0.05,{ }^{b} p<0.001$ 
(Fig. 1). Thyroxine treatment of the rats given PTU resulted in uptake values similar to or higher than those produced by the hormone alone (distribution ratios of 25-27 at ages of 6-16 days).

Thyroxine treatment of donor rats also increased the uptake of $1 \mathrm{~m} M$ leucine by slices from 14-dayold rats by $16 \%$ in a $30 \mathrm{~min}$ incubation $(p<0.05)$. No significant effect was found in tissues from 6or 23-day-old rats.

Effects of length of treatment with thyroxine on AIB uptake by slices from rats of different ages

As noted above, in all of the foregoing tests of thyroxine treatment, the hormone was given from birth until the animals were used, so that length of treatment was different for each age group. Experiments were, therefore, carried out to determine if age of the donor rat or length of thyroxine treatment was more directly related to the lack of response of AIB uptake in 1 day tissues and the apparent change from inhibition to stimulation in going from 6- to 10-day-old brain. The results of Table 1, lines 1-6, show that thyroxine did not alter AIB uptake in slices from either 1- to 3-day rats even when treatment began up to 10 days before pups were born (by injection into pregnant rats). Furthermore, the longer the hormone treatment, the greater the inhibitory effect by 6 days and the greater the stimulation in tissues at 10, 14, or 23 days old (Table 1). The inhibition of uptake in the 6-day tissues was not changed to stimulation by 10 days on the hormone, even though this length of treatment gave stimulation in 10-day old tissues. Likewise, the slices from 10-day-old rats showed stimulation of uptake after 6 days on thyroxine and not the inhibition shown by tissue from 6-day-old rats given the hormone for 6 days.

Triiodothyronine also failed to produce stimulation of AIB transport by brain slices from rats less than 3 days old. Injection of $5 \mu \mathrm{g} / \mathrm{rat}(0.8 \mathrm{mg} / \mathrm{kg}$ body weight) of this compound 2 days before sacrifice was without effect on uptake. A $10 \mu M$ level of this form of the hormone added in vitro did increase uptake of $0.05 \mathrm{mM}$ cycloleucine in 3-day tissues in a $3 \mathrm{~h}$ incubation (distribution ratios of 23.2 \pm 0.6 versus $27.0 \pm 1.26, p<0.05$, for six samples in each group). A 3 or $4 \mathrm{~h}$ period of preincubation with 10 or $40 \mu M$ triiodothyronine did not alter uptake of $0.05 \mathrm{mM}$ AlB by brain slices from 1- or 4day-old rats, however. Shorter times of exposure to either form of the hormone in vitro were uniformly without effect in altering transport of either of these amino acids.

\section{Identification of the brain transport system(s) altered by thyroxine}

The changes in effects of thyroxine on amino acid uptakes with aging strongly suggest that the hormone alters their transport systems in brain over
TABLE 1. The effect of time of treatment with thyroxine on transport of $A I B$ into brain slices from rats of different ages

\begin{tabular}{clll}
\hline $\begin{array}{c}\text { Age in } \\
\text { days }\end{array}$ & $\begin{array}{c}\text { Days on } \\
\text { thyroxine }\end{array}$ & Distribution ratio & $\begin{array}{c}\text { p versus no } \\
\text { thyroxine }\end{array}$ \\
\hline 1 & 0 & $10.45 \pm 0.85(4)$ & \\
& $6^{a}$ & $11.80 \pm 0.11(6)$ & n.s. \\
& $8-10^{b}$ & $10.09 \pm 0.27(16)$ & n.s. \\
3 & 0 & $15.78 \pm 0.35(4)$ & \\
& 3 & $15.89 \pm 0.80(11)$ & n.s. \\
& $13^{c}$ & $14.66 \pm 0.82(3)$ & n.s. \\
6 & 0 & $24.57 \pm 0.87(29)$ & \\
& 6 & $21.66 \pm 0.62(28)$ & $<0.01$ \\
& $11^{c}$ & $17.34 \pm 0.26(7)$ & $<0.01$ \\
10 & 0 & $17.42 \pm 0.56(19)$ & \\
& 6 & $19.86 \pm 0.49(8)$ & $<0.02$ \\
& 10 & $22.10 \pm 1.20(18)$ & $<0.001$ \\
14 & 0 & $19.05 \pm 1.00(18)$ & \\
& $3 / 4$ & $18.26 \pm 0.56(6)$ & n.s. \\
& 6 & $21.45 \pm 1.22(8)$ & n.s. \\
& 10 & $22.03 \pm 0.99(6)$ & n.s. \\
& 14 & $24.51 \pm 0.87(23)$ & $<0.001$ \\
23 & 0 & $16.69 \pm 0.37(25)$ & \\
& 14 & $17.96 \pm 0.78(14)$ & n.s. \\
& 23 & $18.35 \pm 0.73(20)$ & $<0.05$ \\
\hline
\end{tabular}

The hormone was injected subcutaneously into pregnant rats and/or their pups for the lengths of time shown. Pups aged 114 days were given $1 \mu \mathrm{g}$ of thyroxine every other day, whereas those older than 14 days were given $2 \mu \mathrm{g}$ every other day. Amounts of thyroxine injected into pregnant rats are given below. AIB uptake was measured for $1 / 2 \mathrm{~h}$ at a $1 \mathrm{~m} M$ level. Values given are averages of distribution ratios \pm SE for the number of samples in the parentheses.

${ }^{a}$ Mothers received $50 \mu \mathrm{g} /$ day for 6 days.

${ }^{b}$ Mothers received $25 \mu \mathrm{g} /$ day for $8-10$ days.

${ }^{c}$ Mothers received $25 \mu \mathrm{g} /$ day, then pups received $1 \mu \mathrm{g}$ every other day.

${ }^{d}$ n.s. $=$ not significant $(\mathrm{p}>0.05)$

the period 1-14 days. We, therefore, used AIB and MeAIB to characterize these changes, since transports of these amino acids were highly sensitive to thyroxine. The same two types of experiments were used as described earlier for brains from normal rats: the effects of inhibitory conditions on transport and analysis of kinetics of transport (Riggs et al., 1984). Our preliminary studies showed that various inhibitory agents and conditions produced much the same patterns of inhibition in brains from the thyroxine-treated rats as in those from control animals. Such a result is not unexpected, since the change in transport produced by the hormone amounted to only one-third or less of the total uptake; the total characteristics of the transport systems were, therefore, mostly those of the controls. A more exact characterization of the transport system(s) altered by the hormone was made, therefore, by evaluating that portion of the uptake that was lost at 6 days or gained at 10-14 days, a quantity that could be obtained by taking the arithmetic 
difference between the two uptakes (hormonetreated minus control) under the same incubation conditions. Since these differences are measures of the transport modified by thyroxine, their characteristics will show what transport system(s) are altered by the hormone.

\section{Thyroxine-induced changes in amino acid transport systems in brain slices from \\ 6-day-old rats}

Although thyroxine stimulated the uptake of a 1 $\mathrm{m} M$ level of MeAIB in a $30 \mathrm{~min}$ incubation (Fig. 2), five out of seven inhibitory conditions (including 10 $\mathrm{m} M$ MeAIB) brought the values in the hormonetreated tissues significantly below those found in their controls (Table 2 , column 3 versus column 2). One of the two other inhibitors, $10 \mathrm{~m} M$ leucine, also gave a lower value after thyroxine treatment, but the change was not significant statistically. Only with $10 \mathrm{~m} M$ AIB or in the absence of any inhibitor was uptake higher after thyroxine treatment than in control tissues (Table 2).

These results suggest that the effect of thyroxine on MeAIB uptake in slices of 6-day-old rats depended on the total level of amino acids present that used the same transport systems as MeAIB, changing from stimulation to inhibition as the load increased. This explanation is confirmed by comparing the uptakes of different levels of MeAIB in slices from control and thyroxine-treated rats. Figure 3 shows a reciprocal (Lineweaver-Burk) plot of saturable uptake of MeAIB in the thyroxinetreated tissues of this age (the solid lines). The

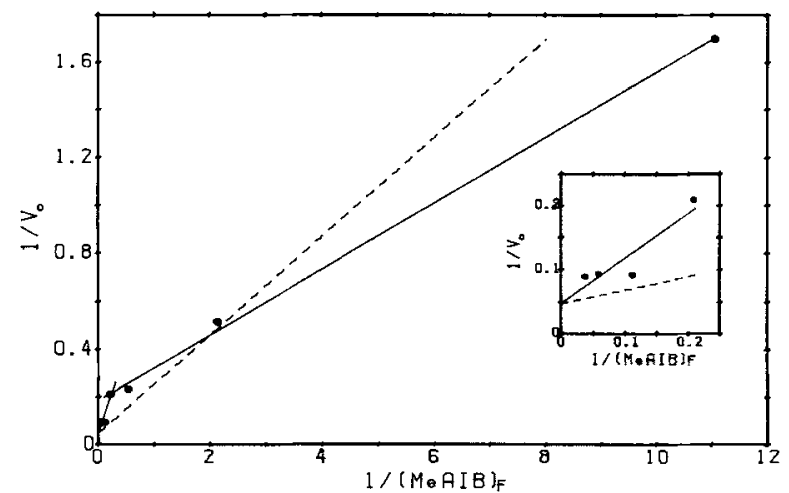

FIG. 3. Reciprocal (Lineweaver-Burk) plot of MeAIB uptake in brain slices from 6-day-old thyroxine-treated rats. MeAlB was at 0.1 to $30 \mathrm{mM}$, and incubation time was $10 \mathrm{~min}$. Nonsaturable entry $(0.12 / 10 \mathrm{~min})$ was calculated by the method of Akedo and Christensen (1962) and subtracted from tota uptake to give saturable uptake $\left(v_{0}\right)$. The solid lines were calculated by the method of least squares to fit the points shown for uptake in the thyroxine-treated tissues. The dashed line represents the uptake of MeAlB under the same conditions in brain slices from 6-day-old control rats (not treated with hormone) (points omitted here for clarity). The two solid lines are significantly different from each other in both slope $(p<0.02)$ and intercept on the ordinate $(p<$ 0.001 ). Two values were averaged for each point shown. dashed line in this figure represents the uptake in control 6-day tissues (Riggs et al., 1984); the points are omitted for clarity. A comparison of the control (dashed) line with that after hormone treatment (solid lines) shows that thyroxine stimulated MeAIB uptake at levels below about $0.5 \mathrm{mM}$ and inhibited it at higher levels. Such a result can be explained by an alteration of the kinetics of uptake, as is readily apparent from the different slopes and $y$ intercepts of the solid lines versus the dashed line of Fig. 3 .

The thyroxine-induced change, however, is not explained entirely as due to a change in kinetics of MeAIB transport by way of system A, the single system it uses in the 6-day control tissues (Riggs et al., 1984). Figure 3 shows a nonlinear uptake after hormone treatment, evidence for which is given by calculation from the points of two lines with significantly different slopes and y intercepts. The thyroxine, therefore, appears to have induced formation of a second transport system used by MeAIB in the 6-day tissue. The appearance of this new system can account in part for the change in kinetics of the uptake.

Figure 4 shows that AIB also was transported by more than one system in slices from thyroxinetreated 6-day-old rats, although it also used only one system in the control brains (Riggs et al., 1984). The results also demonstrate that, in contrast to uptake of MeAIB, the uptake of AIB was lower than normal in the hormone-treated tissues at all levels below about $15 \mathrm{mM}$, but the same, or perhaps higher than normal, at levels above $15 \mathrm{mM}$.

The appearance of a thyroxine-induced, second system at 6 days was shown also by comparing the characteristics of AIB and MeAIB uptakes after thyroxine treatment ${ }^{1}$ with those of the transport lost due to thyroxine. With MeAIB, all inhibitors tested gave a significantly greater effect on one of these measurements than on the other one (Table 2, columns 5-7), while with AIB, statistically significant deviations were given by six of the 14 inhibitors tested (Fig. 5). Most striking with this latter amino acid were the effects of phenylalanine, leucine, and glycine, which inhibited total uptake in the hormone-treated tissues by about $60-70 \%$ without altering the decrement, or perhaps stimulating it somewhat (Fig. 5).

The inhibition studies, therefore, show again that the two test amino acids are not transported to the

\footnotetext{
${ }^{1}$ The comparison was made with values after the thyroxine treatment, rather than with controls, since transport was decreased due to the hormone. That portion of the transport lost due to thyroxine is included in the controls, but is not present after hormone treatment. The most significant comparison, therefore, is that of the characteristics of the transport system(s) changed by thyroxine (i.e., lost) versus those that remain after the loss.
} 
TABLE 2. Inhibition of transport of MeAIB into brain slices from 6-day-old rats with and without prior thyroxine treatment

Saturable entry ${ }^{a}$ in:

\begin{tabular}{|c|c|c|c|c|c|c|}
\hline \multirow[b]{2}{*}{ Inhibitor } & \multicolumn{3}{|c|}{ Saturable entry ${ }^{a}$ in: } & \multicolumn{3}{|c|}{$\%$ Inhibition of saturable entry for: } \\
\hline & Control & Thyroxine-treated & $\mathrm{p}$ & Thyroxine-treated $^{d}$ & $\begin{array}{l}\text { Change } \\
\text { due to } \\
\text { thyroxine }\end{array}$ & $\mathrm{p}$ \\
\hline None & $13.23 \pm 0.68$ & $15.01 \pm 0.55$ & $<0.05$ & - & - & - \\
\hline Incubate at $18^{\circ} \mathrm{C}$ & $0.14 \pm 0.07$ & $-0.45 \pm 0.17$ & $<0.01$ & $103 \pm 1.1$ & $133 \pm 9.5^{c}$ & $<0.02$ \\
\hline pH 5.4 (Pi buffer) & $8.57 \pm 0.37$ & $5.74 \pm 0.31$ & $<0.001$ & $62 \pm 2.1$ & $259 \pm 18^{c}$ & $\ll 0.001$ \\
\hline $10 \mathrm{~m} M \mathrm{AIB}$ & $2.97 \pm 0.15$ & $4.30 \pm 0.19$ & $<0.001$ & $71 \pm 1.3$ & $25 \pm 11$ & $<0.01$ \\
\hline $10 \mathrm{~m} M \mathrm{MeAIB}$ & $4.43 \pm 0.48$ & $2.33 \pm 0.32$ & $<0.02$ & $84 \pm 2.1$ & $218 \pm 18^{c}$ & $<0.001$ \\
\hline $10 \mathrm{~m} M$ Leucine & $10.73 \pm 0.62$ & $8.78=0.45$ & n.s. ${ }^{b}$ & $42 \pm 3.0$ & $209 \pm 25^{c}$ & $<0.001$ \\
\hline $10 \mathrm{~m} M$ Phenylalanine & $10.47 \pm 0.33$ & $5.07 \pm 0.37$ & $<0.001$ & $66 \pm 2.4$ & $404 \pm 21^{c}$ & $\ll 0.001$ \\
\hline $10 \mathrm{~m} M$ Valine & $10.57 \pm 0.36$ & $6.15 \pm 0.39$ & $<0.001$ & $59 \pm 2.6$ & $349 \pm 22^{c}$ & $\ll 0.001$ \\
\hline
\end{tabular}

Tissues were incubated $30 \mathrm{~min}$ with $1 \mathrm{mM}$ MeAIB with the condition or addition shown in column 1 . Values in columns 2 and 3 are saturable uptakes, obtained by subtracting nonsaturable entry from total uptake. Nonsaturable entry was found to be 0.11 and $0.36 / 30$ min in control and hormone-treated tissues, respectively, as determined by the method of Akedo and Christensen (1962). The numbers are averages of 5-17 values \pm SEM in each case.

${ }^{a} \mu \mathrm{mol} / \mathrm{ml}$ cellular water $/ 30 \mathrm{~min}$

${ }^{b}$ n.s. = not significant $(\mathrm{p}>0.05)$

${ }^{c}$ Inhibition significantly greater than $100 \%(\mathrm{p}<0.02$ to $\mathrm{p}<0.001)$

${ }^{d}$ [Entry in presence of inhibitor (column 3) $\left.\times 100\right] /[$ Entry in absence of inhibitor (column 3, line 1)]

$e$ [Difference between columns 2 and $3 \times 100] /[$ Difference between columns 2 and 3 , line 1]

same extent by the same systems in the controls compared with the thyroxine-treated tissues. They are thus consistent with the kinetic data discussed above, suggesting appearance of a second transport system used by both AIB and MeAIB in brain slices from the 6-day-old thyroxine-treated rats.

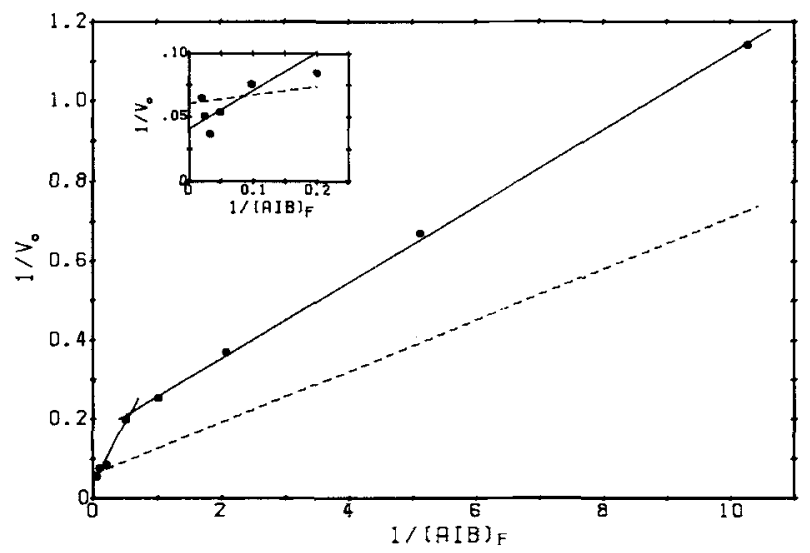

FIG. 4. Reciprocal (Lineweaver-Burk) plot of AIB uptake in brain slices from 6-day-old thyroxine-treated rats. AlB was at 0.1 to $50 \mathrm{mM}$ and incubation time was $10 \mathrm{~min}$. The solid lines were calculated as best fits to the points shown, as described in the legend to Fig. 3 . Nonsaturable entry was $0.07 / 10 \mathrm{~min}$. The dashed line (points omitted) represents AIB uptake in control slices from 6-day-old rats, and is taken from Riggs et al. (1984). The two solid lines are significantly different from each other in both slope and intercept on the ordinate ( $p<0.001$ in both cases). Two to four values were averaged for each point shown.
Thyroxine-induced changes in transport systems in brain slices from 14-day-old rats

Thyroxine treatment for 14 days resulted in stimulation of transports of MeAIB, AIB, and leucine (see above). Inhibition studies with the first two amino acids showed that the additional uptake produced by thyroxine was probably completely $\mathrm{Na}^{+}$dependent and highly temperature-sensitive (Table 3 , columns 3 and 6 ). Strong inhibition of the increment was given also by $10 \mathrm{~m} M$ AIB, alanine, serine, cycloleucine, or glycine. With AIB, six of the 15 conditions tested showed significantly less inhibition of the increment than of the total saturable uptake in the controls (compare columns 2 and 3 of Table 3, and see the p values in column 4). For MeAIB uptake, in contrast, inhibition of the thyroxine stimulation was greater than inhibition of total saturable uptake in all but two of the conditions tested (i.e., in the presence of leucine or valine) (Table 3 , column 5 versus column 6 , with $p$ values in column 7). These results show that the increment in uptake produced by the hormone had different characteristics than did the uptake of these amino acids in tissues from rats not treated with thyroxine.

Reciprocal plots of uptakes of different levels of AIB and MeAIB at 14 days gave nonlinear curves after hormone treatment, as was also found for control tissues (Riggs et al., 1984). The position of the best-fitting line for the low $K_{\mathrm{m}}$ system was markedly below the corresponding control (shown in Fig. 6 for AIB), a change that shows again the stimulation of uptakes of low levels of these amino acids in response to the thyroxine. The stimulation was 


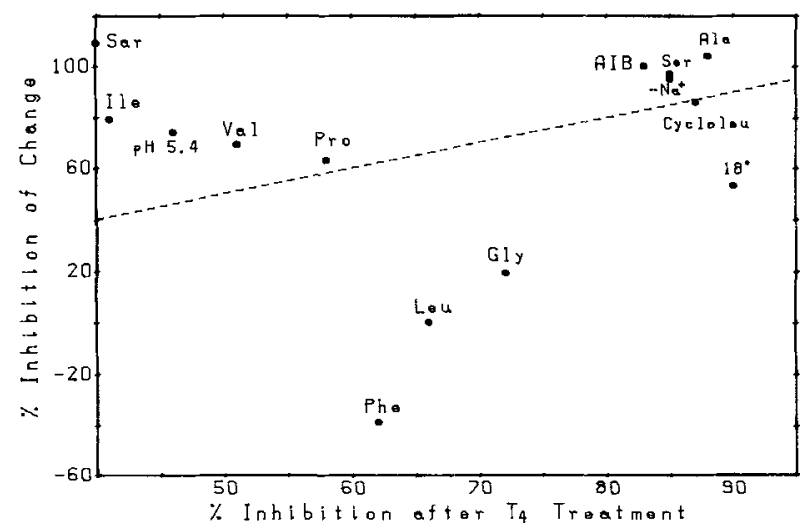

FIG. 5. Effects of inhibitory conditions on uptake of AIB in brain slices from 6-day-old thyroxine $\left(T_{4}\right)$-treated rats compared with effects on the thyroxine-induced change in uptake produced by the hormone. The various conditions and agents were used as inhibitors of uptake of $1 \mathrm{mM}$ AIB in 30 min incubations in brain slices from control and thyroxinetreated rats. The change in uptake due to hormone treatment was calculated under each condition by subtracting saturable uptake (hormone-treated) from saturable uptake (control); these values then were expressed as percent inhibition relative to thyroxine-induced change in uptake found in the absence of inhibitor (See Table 2, footnote e). The results are shown on the ordinate. The abscissa records the percent inhibition produced when the slices from the thyroxinetreated rats were incubated under each condition (see Table 2 , footnote d). Nonsaturable entry $(0.05 / 10 \mathrm{~min}$ for controls, $0.07 / 10 \mathrm{~min}$ after thyroxine treatment) was subtracted from the total uptake in each case to obtain the saturable entry used in the calculation. Four to 29 values were averaged to obtain the number used for calculating each point shown. The inhibitor symbols used are: $-\mathrm{Na}^{+}, \mathrm{Na}^{+}$-free incubation medium; $18^{\circ} \mathrm{C}$, incubation carried out at this temperature; $\mathrm{pH} 5.4$, incubated in phosphate buffer at this $\mathrm{pH}$; Sar, $10 \mathrm{mM}$ sarcosine; Cycloleu, $10 \mathrm{mM}$ cycloleucine. Other symbols are standard abbreviations for amino acids or are as previously defined. Each inhibitor amino acid was at a $10 \mathrm{mM}$ level. The dashed line shows where the points would fall if the inhibitory conditions produced the same quantitative effect on each of the two measurements. Statistically significant differences were found at $18^{\circ} \mathrm{C}$, and in the presence of serine, glycine, leucine, isoleucine, or phenylalanine.

greatest below about $5 \mathrm{~m} M$ but was more difficult to demonstrate at high levels of either amino acid because of the small change relative to the large total uptake.

\section{Kinetics of AIB uptake in brain slices from 1-day-old thyroxine-treated rats}

Although the hormone did not alter transport of a $1 \mathrm{mM}$ level of AIB in 1-day tissues, the above results suggested that an effect might be found if the proper amino acid level was used. Ten minute uptakes were measured, therefore, in thyroxinetreated 1-day-old tissues at AIB levels of 0.2-40 $\mathrm{m} M$ and the results compared with those from control tissues studied in this same way and reported earlier (Riggs et al., 1984). Reciprocal plots, 1/ [AIB] $]_{\mathrm{f}}$ versus $1 / \mathrm{v}_{0}$, showed two significantly different lines in the hormone-treated tissues, as they did in controls, and the saturable uptakes were essentially the same in control and hormone-treated tissues at all AIB levels tested. They failed, therefore, to show any effect of thyroxine on uptake at any of the levels used for this amino acid in 1-day tissues. The results also confirmed the presence of at least two transport systems used by AIB at this age.

\section{DISCUSSION}

Brain slices from rats of different ages showed quite different sensitivities of their transports to thyroxine treatment. No response could be found in 1-day-old tissues even when thyroxine treatment began as much as 10 days earlier by injecting the hormone into pregnant rats. An inhibition was found in 6-day tissues at most physiological amino acid loads (see further discussion below), while stimulation was produced in tissues 10 days or older. Treating donor rats with thyroxine for different lengths of time modified only the amount of inhibition or stimulation of AIB uptake but did not change the type of effect (Table 1). The results suggest that the response to the hormone is characteristic of each age and, therefore, that the transport systems used by AIB are different at 1 day than at 6 days and different again at ages beyond 6 days.

Not only was AIB transport different after thyroxine was injected, but it was decreased markedly when donor rats were given the anti-thyroid agent, PTU (Fig. 1). At 6 days, both the hormone and PTU inhibited AIB uptake, but PTU had a much greater effect. Since the control rats still had their endogenous thyroid hormones, the magnitude of the difference in AIB uptake due to thyroxine is shown best by comparing the results after PTU treatment with those after thyroxine treatment. On this basis, it can be seen from Fig. 1 that the hormone produced a $50-70 \%$ increase in uptake at all ages studied with PTU, including at 6 days. The PTU results show that thyroid hormone is necessary for the normal development of neutral $\alpha$-amino acid transport systems in the developing rat brain, since uptake in tissues from PTU-treated rats never reached levels much above those found at 1 day (Fig. 1).

A more detailed analysis showed that pretreatment of donor rats with thyroxine changed the transport systems used by AIB and MeAIB at both 6 and 14 days, modifying the changes that occur normally during development. In the 6-day-old tissues, the hormone led to use of a second system in addition to the single system, system $A$, used normally by these amino acids at this age. This conclusion is based primarily on two types of evidence found for both amino acids: the different inhibition characteristics of that part of their uptakes altered by the hormone compared with those found in the 
TABLE 3. Inhibition of transports of AIB and MeAIB into brain slices of 14-day-old rats with and without thyroxine treatment

\begin{tabular}{|c|c|c|c|c|c|c|}
\hline & \multicolumn{6}{|c|}{$\%$ Inhibition of saturable entry of: } \\
\hline & \multicolumn{3}{|c|}{ AIB uptake } & \multicolumn{3}{|c|}{$N$-Methyl AIB uptake } \\
\hline & Control & $\begin{array}{l}\text { Increment } \\
\text { due to } \\
\text { thyroxine }\end{array}$ & $\mathrm{p}$ & Control & $\begin{array}{l}\text { Increment } \\
\text { due to } \\
\text { thyroxine }\end{array}$ & $\mathrm{p}$ \\
\hline $\mathrm{Na}^{+}$-free medium & $91 \pm 0.6$ & $93 \pm 2.8$ & n.s. ${ }^{b}$ & $97 \pm 0.6$ & $109 \pm 2.6$ & $<0.001$ \\
\hline Incubate at $18^{\circ} \mathrm{C}$ & $81 \pm 0.8$ & $68 \pm 3.0$ & $<0.001$ & $97 \pm 1.5$ & $110 \pm 2.4$ & $<0.01$ \\
\hline pH 5.4 (Pi buffer) & $33 \pm 1.1$ & $53 \pm 12$ & n.s. & $36 \pm 4.4$ & $86 \pm 9.0$ & $<0.001$ \\
\hline $10 \mathrm{~m} M$ AIB & $82 \pm 1.7$ & $71 \pm 20$ & n.s. & $48 \pm 7.1$ & $89 \pm 6.2$ & $<0.01$ \\
\hline $10 \mathrm{~m} M$ MeAIB & $52 \pm 4.8^{c}$ & $-13 \pm 11^{c}$ & $<0.001$ & $61 \pm 1.5$ & $80 \pm 3.4$ & $<0.001$ \\
\hline $10 \mathrm{~m} M$ Alanine & $81 \pm 2.7$ & $89 \pm 4.6$ & n.s. & $65 \pm 2.2$ & $80 \pm 3.2$ & $<0.01$ \\
\hline $10 \mathrm{~m} M$ Serine & $83 \pm 2.5$ & $72 \pm 3.7$ & $<0.02$ & - & - & 一 \\
\hline $10 \mathrm{~m} M$ Proline & $64 \pm 3.5$ & $34 \pm 12$ & $<0.001$ & - & - & - \\
\hline $10 \mathrm{~m} M$ Cycloleucine & $83 \pm 0.4$ & $84 \pm 3.2$ & n.s. & - & - & - \\
\hline $10 \mathrm{~m} M$ Glycine & $72 \pm 0.7$ & $75 \pm 2.0$ & n.s. & - & - & - \\
\hline $10 \mathrm{~m} M$ Sarcosine & $51 \pm 2.2$ & $44 \pm 5.3$ & n.s. & 一 & - & - \\
\hline $10 \mathrm{~m} M$ Leucine & $58 \pm 1.0$ & $50 \pm 8.4$ & n.s. & $38 \pm 3.8$ & $44 \pm 18$ & n.s. \\
\hline $10 \mathrm{~m} M$ Isoleucine & $69 \pm 2.2$ & $31 \pm 5.4$ & $<0.001$ & - & - & - \\
\hline $10 \mathrm{~m} M$ Valine & $63 \pm 2.4$ & $58 \pm 17$ & n.s. & $59 \pm 1.9$ & $16 \pm 11$ & $<0.01$ \\
\hline $10 \mathrm{~m} M$ Phenylalanine & $58 \pm 1.5$ & $43 \pm 4.4$ & $<0.01$ & $18 \pm 1.6$ & $73 \pm 7.7$ & $<0.001$ \\
\hline
\end{tabular}

General conditions were as described in the legend to Table 2. Amino acid was at a $1 \mathrm{~m} M$ level; incubation time was $30 \mathrm{~min}$ for MeAIB and an average of values from 30 and $60 \mathrm{~min}$ incubations for AIB. Values are calculated for saturable entry; nonsaturable entry was 0.39 and $0.21 / 30 \mathrm{~min}$ for AIB in control and hormone-treated tissues, respectively, and 0.44 and $0.29 / 30 \mathrm{~min}$ for MeAIB in control and hormone-treated tissues, respectively. Values are averages \pm SEM for 6-45 samples each for AIB, and 6-14 samples each for MeAIB.

a See Table 2, footnote $e$, for method of calculation.

${ }^{b}$ n.s. = not significant statistically $(\mathrm{p}>0.05)$.

c $20 \mathrm{~m} M$ MeAIB used.

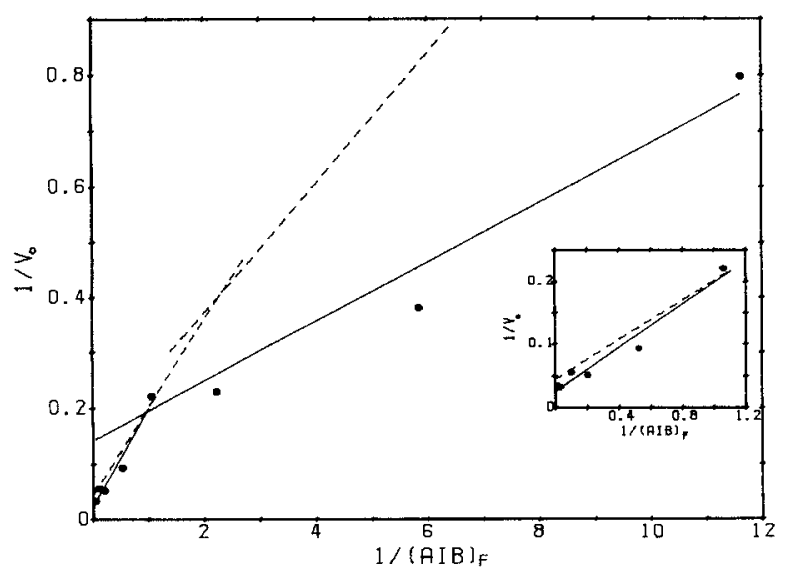

FIG. 6. Reciprocal (Lineweaver-Burk) plot of AIB uptake in brain slices from 14-day-old thyroxine-treated rats. AIB was at 0.1 to $60 \mathrm{mM}$ and incubation time was $10 \mathrm{~min}$. The solid lines were calculated as best fits to the points as described in the legend to Fig. 3 . Nonsaturable entry was $0.05 / 10 \mathrm{~min}$. The dashed lines (points omitted) represent AIB uptake in control slices from 14-day-old rats and is taken from Riggs et al. (1984). The two solid lines are significantly different from each other in both slope $(p<0.001)$ and intercept on the ordinate $(p<0.05)$. Two to eight values were averaged for each point shown. thyroxine-treated tissues, and the presence of nonlinear reciprocal kinetic plots for uptakes in the hormone-treated tissues compared with single linear plots in the controls. The kinetic changes were such that uptakes of both amino acids were decreased at some levels and not changed or increased at other levels (Figs. 3 and 4). AIB, MeAIB, and alanine all showed less uptake after thyroxine treatment when their levels approximated the total physiological blood load of amino acids that use the same systems they do, i.e., around 1-2 $\mathrm{m} M$. A decreased uptake, occurring at the same time that a second system became functional, shows that the normal, highly active 6-day system $\mathrm{A}$ was disappearing at the same time that a less active system was being formed. The decreased use of system $\mathrm{A}$ was greater than shown by the decrement in uptake, however, because of the appearance and use of the new system.

The changes induced by thyroxine at 6 days produced transports similar to those found in normal brain slices taken from donor rats as they aged beyond 6 days, i.e., a decrease in uptake of AIB and MeAIB by system A accompanied by the appearance of a second system (Riggs et al., 1984). In addition, treatment with thyroxine for 11 days (begun by injecting the hormone into pregnant rats) led to an even greater decrease in AIB uptake in 6- 
day slices than found after treatment for 6 days (Table 1), an indication that transitional development of the transport systems had gone even further in these 6-day postnatal brains than found after 6 days of treatment. These facts suggest that the hormone acted by accelerating the development of the amino acid transport systems so that the 6-day brain had transport properties not normally occurring until later (i.e., by 10-14 days). Such an action should not be unexpected, since thyroid hormone has been found to accelerate the rate of development of brain in a number of other ways: e.g., it hastens brain cell formation and differentiation (Balázs and Richter, 1973; Pelton and Bass, 1973; Lauder, 1977), accelerates metabolic maturation of the brain (Balázs and Richter, 1973), and increases the rate of behavioral development (Schapiro, 1968; Schapiro et al., 1970).

On the other hand, the stimulating action of the hormone after 14 days appears to result from an increased activity of one or both of the systems present at that time rather than from a further acceleration of the development of brain transport systems. Normal development beyond 14 days did not result in greater uptake than at 14 days; if anything, it declined. The uptakes of AIB and MeAIB were higher in the 14-day hormone-treated tissues than in control tissues at any age studied (up to 30 days) (Figs. 1 and 2).

The characteristics of the new transport produced at 14 days by thyroxine (i.e., the increment, uptake after thyroxine treatment minus uptake in controls) were different from those found in control tissues, a fact suggesting that the hormone did not influence both of the 14-day transport systems to the same extent. Furthermore, the characteristics were not the same for AIB as they were for MeAIB (Table 3). The results may be explained if thyroxine acts on both of the 14-day systems, but AIB and MeAIB have a different quantitative division of their transports between the two systems. We have shown already that these two amino acids probably do not share the same transport systems to the same extent in control 14-day-old brain slices (Riggs et al., 1984). The characteristics of the increment in uptake of MeAIB suggest that most or all of its stimulation may involve system A: the increment was highly sensitive to $\left[\mathrm{Na}^{+}\right]$, temperature, $\mathrm{pH}$, and high levels of the A-system amino acids, MeAIB, AIB, and alanine, while affected much less by leucine and valine (Table 3, column 6). In contrast, the thyroxine-induced increment in uptake of $1 \mathrm{~m} M$ AIB was not inhibited by $20 \mathrm{~m} M$ MeAIB, it showed relatively little inhibition by proline, and it was much less sensitive to decreased temperature and $\mathrm{pH}$ than was the increment in MeAIB uptake (Table 3, column 3). Uptake of AIB at this level would appear, therefore, to be increased by way of both system $A$ and the new system it normally uses after 6 days. The difference between effects on the two amino acids is undoubtedly a consequence of a much lower affinity of MeAIB for the new transport system relative to AIB, as is suggested by the much higher level of MeAIB needed before curvature occurs in the Lineweaver-Burk plots. The results may be explained if we conclude that a $1 \mathrm{mM}$ level of MeAIB is transported almost entirely by system A, while this level of AIB uses both systems. A stimulation of the new system by thyroxine then would show up when $1 \mathrm{~m} M$ AIB was tested, but not when $1 \mathrm{~m} M$ MeAIB was used.

The identity of the second thyroxine-sensitive 14day system is not clear from the data. Sershen and Lajtha (1979) have distinguished at least seven transport systems in newborn and adult mouse brain for the different neutral amino acids. In addition to systems A, L, and ASC, other individual systems were suggested for transporting $y$-aminobutyric acid, glycine, proline, and taurine. It is possible that one of these last four systems is thyroxine-sensitive and used by AIB and MeAIB at 14 days. The second system is probably not ASC, however, since thyroxine treatment for 14 days did not alter uptake of alanine (Fig. 2), one of the substrates originally used to define this system (Christensen et al., 1967). System L is a more likely possibility. Thyroxine increases transport of leucine, a major system $\mathrm{L}$ amino acid, at 14 days but not at 6 days. Furthermore, AIB uses system $L$ at ages beyond 6 days (Riggs et al., 1984), perhaps enough by 14 days that a $1 \mathrm{~m} M$ level responds to a possible thyroxine stimulation of this system.

Acknowledgment: This work was supported in part by grant AM-03709 from the National Institutes of Health, U.S. Public Health Service.

\section{REFERENCES}

Akedo H. and Christensen H. N. (1962) Nature of insulin action on amino acid uptake by the isolated diaphragm. J. Biol. Chem 237, 118-122.

Balázs R. and Richter D. (1973) Effects of hormones on the biochemical maturation of the brain, in Biochemistry of the Developing Brain, Vol. 1 (Himwich W., ed), pp. 253-299. Marcel Dekker, New York.

Christensen H. N., Liang M., and Archer E. G. (1967) A distinct $\mathrm{Na}^{+}$-requiring transport system for alanine, serine, cysteine, and similar amino acids. J. Biol. Chem 242, $5237-$ 5246.

Daniel P. M., Love E. R., and Pratt O. E. (1975) Hypothyroidism and amino acid entry into brain and muscle. Lancet 2,872 .

Dobbing J. (1971) Undernutrition and the developing brain: the use of animal models to elucidate the human problem, in Advances in Experimental Medicine and Biology, Vol. 13: Chemistry and Brain Development (Paoletti R. and Davison A. N., eds), pp. 399-412. Plenum Press, New York.

Eayrs J. T. (1961) Age as a factor determining the severity and 
reversibility of the effects of thyroid deprivation in the rat. J. Endocrinol, 22, 409-419.

Geel S. E., Valcana T., and Timiras P. S. (1967) Effect of neonatal hypothyroidism and of thyroxine on $\mathrm{L}-\left[{ }^{14} \mathrm{C}\right]$ leucine incorporation in protein in vivo and the relationship to ionic levels in the developing brain of the rat. Brain Res. 4, 143150.

Gelber S., Campbell P. L., Deibler G. E., and Sokoloff L. (1964) Effects of L-thyroxine on amino acid incorporation into protein in mature and immature rat brain. $J$. Neurochem. 11, 221-229.

Hamburgh M., Lynn E., and Weiss E. P. (1964) Analysis of the influence of thyroid hormone on prenatal and postnatal maturation of the rat. Anat. Rec. 150, 147-162.

Lauder J. M. (1977) The effects of early hypo- and hyperthyroidism on the development of rat cerebellar cortex. III. Kinetics of cell proliferation in the external granular lay,er. Brain Res. 126, 31-51.
Pelton E. W. and Bass N. H. (1973) Adverse effects of excess thyroid hormone on the maturation of rat cerebrum. Arch. Neurol. 29, 145-150.

Riggs T. R., Pote K. G., Im H.-S., and Huff D. W. (1984) Developmental changes in the neutral $\alpha$-amino acid transport systems of rat brain over the first three weeks after birth. J. Neurochem. 42, 1251-1259.

Schapiro S. (1968) Some physiological, biochemical, and behavioral consequences of neonatal hormone administration: cortisol and thyroxine. Gen. Comp. Endocrinol. 10, 214228.

Schapiro S., Salas M., and Vukovich K. (1970) Hormonol effects on ontogeny of swimming ability in the rat: assessment of central nervous system development. Science 168, 147150.

Sershen H. and Lajtha A. (1979) Inhibition pattern of analogs indicates the presence of ten or more transport systems for amino acids in brain cells. $J$. Neurochem. 32, 719-726. 